\title{
OBRAS DE ERUDICIÓN POÉTICA Y POLIANTEAS
}

\author{
Alfonso VÁzQuez VÁzQuez \\ a.v.vazquez@gmail.com
}

\section{RESUMEN}

Durante los siglos XVI y XVII prolifera la edición de obras de carácter enciclopédico que tratan de ordenar con diversos criterios los conocimientos provenientes de la Antigüedad grecolatina. Han sido estudiadas parcialmente las denominadas polianteas (del griego «muchas flores») y la influencia que ejercieron en diversos autores del Siglo de Oro español. Tras un preliminar histórico y crítico, en este artículo se analizan algunas de las obras más importantes de estas características y se pone de relieve el creciente cuidado con que se ordenaron sus contenidos y, en consecuencia, su perfeccionamiento como obras de consulta.

Palabras Clave: Poliantea, erudición, imitación, Siglo de Oro, enciclopedia.

\section{AbStRact}

In the 16th and 17th centuries, editing of encyclopedic works that deals with ordering the knowledge of Greco-Roman antiquity with diverse criterias was widespread. The so-called poliantheas (from the Greek words 'many flowers') and the influence exerted on various writers of the Spanish Golden age have been partially studied. After a historical and critical preliminary, this article examines some of the most important features of these works and highlights the care with which its contents were ordered and, consequently, its further development as reference works.

KEY WORDS: Polyanthea, erudition, imitation, Spanish Golden Age, encyclopedia. 


\section{INTRODUCCIÓN}

Puede y debe realizarse un cotejo más exhaustivo de los poetas de primera fila del Siglo de Oro y sus fuentes de erudición, pero los llevados a cabo hasta la fecha son muestra de algo que parece lógico suponer: que los poetas, grandes o pequeños, no tuvieron por qué descartar la utilización de fuentes de segunda mano para la composición de sus obras, o que dichos temas habían alcanzado tal grado de difusión -tanto en obras de erudición como en el tratamiento poético de los temas y motivos clásicos- que hará difícil distinguir si la erudición de unos y otros es de primera o de segunda mano, distinción, por otra parte, quizá no muy relevante ${ }^{1}$. El caso de Lope de Vega, cuya comparación con las Officinae de Ravisio Textor no ofrece lugar a la duda, demuestra que lo que hoy sin duda llamaríamos plagio entonces se denominó erudición, si bien -al igual que hoy- solía ocultarse el lugar de donde provenía ${ }^{2}$. Esta ocultación corrobora, además, que las ideas de autoría intelectual, originalidad y plagio no son ajenas a los autores del Siglo de Oro.

Para hacerse una idea de la proliferación de obras de carácter erudito y polianteas durante los siglos XVI y XVII puede verse el repertorio de Sagrario López Poza ${ }^{3}$ y, sobre todo, el proyecto de investigación que ella misma dirige en la Facultade de Filoloxía de A Coruña: «Poliantea. Enciclopedias, repertorios de lugares comunes y misceláneas de erudición humanística» ${ }^{4}$. Faltan traducciones de estas obras -que se escribieron mayoritariamente en latín-, tipologías y estudios generales desde diversos puntos de vista que aclaren sus significados y alcance real. La bibliografía de López Poza es una primera aproximación que recoge obras de muy variada índole, pues incluye desde estudios de retórica y poética de raigambre clásica hasta ayudas a la predicación. De acuerdo con la misma autora, quien aduce la autoridad de Marcel Bataillon ${ }^{5}$, puede verse el precedente de estas obras en los cuadernos, cartapacios o excerptae donde frecuentemente el humanista de la primera mitad del siglo XVI recogía las citas y lugares que le habían llamado la atención con el objeto de utilizarlos posteriormente en sus obras o discursos.

\footnotetext{
1 Pueden verse, entre otros muchos: Dámaso Alonso (1948): Vida y obra de Medrano, Madrid, Consejo Superior de Investigaciones Científicas, Instituto Antonio de Nebrija; Antonio Vilanova (1957): Las fuentes y los temas del Polifemo de Góngora, Madrid, Consejo Superior de Investigaciones Ciéntificas; Alan S. TRUEBLOoD (1958): «The Officina of Ravisius Textor in Lope de Vega's Dorotea», Hispanic Review, vol. 36, n. ${ }^{\circ} 2$, pp. 135-141. Simón Anselmo Vosters (1982): «Lope de Vega y Juan Ravisio Textor. Nuevos datos», Actas del cuarto congreso internacional de hispanistas, pp. 785-818, Salamanca, Universidad; Aurora EGIDO (1988): «Lope de Vega, Ravisio Textor y la creación del mundo como obra de Arte», Homenaje a Eugenio Asensio, pp. 171-184, Madrid, Gredos; etc.

2 Puede verse un compendio de la atención crítica que ha merecido la relación de Lope de Vega con la obra de Ravisio Textor en Julián GonzÁlez-BARRera (2007): «Lope de Vega y los "librotes de lugares comunes": su lectura particular de Ravisio Téxtor», Anuario Lope de Vega 13, pp. 51-72, Barcelona, Universitat Autònoma, p. 51, nota 1. El mismo artículo ofrece además nuevas comparaciones.

3 Sagrario López Poza (1990): «Florilegios, polyantheas, repertorios de sentencias y lugares comunes. Aproximación bibliográfica», Criticón 49, pp. 61-76, Université de Toulouse II-Le Mirail, Institut d'Etudes Hispaniques.

4 También la Universität Mannheim desarrolla un proyecto de interés para el estudio de las polianteas y obras de erudición de la Edad Moderna. Bajo el título Thesaurus Eruditionis reúne los proyectos: «Corpus Automatum Multiplex Electorum Neolatinitatis Auctorum» (CAMEMA) y «Structured Vocabulary of Early Modern Knowledge» (TERMINI). Puede verse en http://www.uni-mannheim.de/mateo/camenahtdocs/ camenaref_e.html (14/01/2012).

5 Sagrario Lopéz Poza (1990), op. cit., p. 61. Aduce el pasaje de Marcel Bataillon (1963-1964): «Sur l'humanisme du Docteur Laguna», en Romance Philology XVII, 2, p. 232.
} 
El hábito de tomar notas personales con el fin de facilitar el aprendizaje o resumir los conocimientos aportados por otros no es, desde luego, una innovación renacentista. Puede documentarse en el tiempo de Jenofonte (s. IV a.C.), quien atribuye a Sócrates -quizá infundadamente- la recomendación de recoger por escrito los lugares ajenos que al filósofo le conviene tener presente ${ }^{6}$. Por otra parte, se puede aducir un variado arco de precedentes de las compilaciones del saber humanístico: desde la poesía gnómica de Focílides y Teognis (s. VI a.C.) hasta las Etimologiae de san Isidoro (s. vII), a cuya sombra se sitúa un buen número de florilegios, examplaria, misceláneas, paremiologías y teatros que persiguen de lejos el mismo propósito?

No obstante, será precisamente cuando el humanista sienta la necesidad de reunir sus conocimientos, autoridades y citas en una suerte de cartapacio personal que la imprenta colme esta falta. No solo se editan entonces las reflexiones personales de Erasmo a partir de sus citas preferidas -Adagiorum collectanea (1500) y Adagiorum chiliades (1508)- sino que, además, el aumento del caudal de conocimientos que se produce con el descubrimiento de la Antigüedad grecolatina, el desarrollo incipiente de las ciencias y los nuevos descubrimientos geográficos conllevan un auge editorial de obras que tratan de compendiar y sistematizar la naciente erudición. Los conocimientos disponibles ya no caben en obras sencillas ni sus contenidos pueden organizarse de acuerdo con los principios medievales de división de las artes y de las ciencias. Tras la eclosión del humanismo, las compilaciones de sabiduría medievales o las obras magnas de un solo autor dan paso a obras de carácter enciclopédico que se amplían con el paso de los años y en las que colaboran varios autores de varias generaciones.

\section{El USO DE LAS OBRAS DE ERUDICIÓN PARA LA CREACIÓN POÉTICA}

Dada la magnitud y complejidad del fenómeno, conviene distinguir varios tipos entre las obras de erudición y compendios del saber. Al menos: obras de carácter general, obras específicas de determinada ciencia o disciplina, obras para la predicación y obras para la creación poética. Interesan ahora aquellas que tienen la intención explícita de ayudar en la creación poética o bien nos consta que fueron utilizadas con este propósito, si bien de cualquiera de ellas puede el poeta extraer materiales, temas, datos, motivos o inspiración. Algunas de estas obras -orientadas a oradores, poetas, estudiantes, comentaristas y críticos- tratan de sistematizar los motivos literarios procedentes de diversos autores con el fin práctico de elaborar repertorios, más o menos organizados, de elementos que sirvan tanto para imitar como para avivar la imaginación. Se ordenan alfabéticamente sustantivos acompañados de epítetos pertinentes y autorizados, se crean diccionarios en los que es posible consultar episodios mitológicos sin necesidad de leer a Homero o a Ovidio, se editan repertorios temáticos organizados en torno a lemas caprichosos pero

6 Lo cita Ángel Ruiz Pérez (2008): «Antologías de textos griegos de la Antigüedad al Siglo de Oro en España», El humanismo español entre el Viejo Mundo y el Nuevo, pp. 347-360. Universidad de León / Universidad de Jaén, p. 347. Puede verse el pasaje en griego y su traducción al inglés en Perseus: Xen, Memorabilia I, 6, 14.

7 Puede verse un interesante planteamiento para ampliar el campo de estudio de la historia de la lexicografía española incluyendo este tipo de obras medievales en Elmar EGGERT (2008): «Las enciclopedias medievales como precursoras de diccionarios. Presentación de las tradiciones españolas del Liber de propietatibus rebus de Bartolomé Inglés», El diccionario como puente entre las lenguas y culturas del mundo. Actas del II Congreso Internacional de Lexicografía Hispánica, Alicante, Biblioteca Virtual Miguel de Cervantes, pp.74-81. 
sugerentes, etc. Todos estos materiales literarios presentan una organización en ocasiones precaria, pero el intento de sistematizar este conocimiento es sintomático del grado de desarrollo que ha alcanzado la práctica de la imitación, sin el cual sería imposible e innecesario elaborar estos manuales. Es decir, la pretensión deliberada de estas obras no es solo el afán taxonómico de la época, sino también la sistematización de un repertorio apto para la imitación. Así lo afirma Lázaro Carreter refiriéndose a Epithetorum opus: «Algunas compilaciones, como las muy conocidas de Ravisio Textor, no tenían otra finalidad que sistematizar un repertorio útil para la imitación. No son enciclopedias para descifrar tanto como recetas ordenadas para cifrar, para componer ${ }^{8}$. Este juego de cifrado es el que llevaron a cabo masivamente multitud de autores del Siglo de Oro, cultos y llanos, en mayor o menor medida. Por este motivo, con la finalidad de elaborar el poema, resultarían de gran ayuda los libros de erudición, pues en ellos podía encontrarse el epíteto deseado, una genealogía mitológica o un episodio clásico adecuado para ser utilizado como exemplum, todo ello avalado por la tradición culta, esto es, por la erudición.

No obstante, ni toda poliantea se concibió con el afán expreso de ayudar en la creación poética u oratoria ni cualquiera de ellas es válida para esta finalidad. A menudo su existencia está ligada a las escuelas de gramática y de retórica. En muchos casos resultan útiles para la práctica de la lengua y versificación latinas, cuyo aprendizaje se desarrollaba también mediante el método de la imitación. Otras, incluso, parecen diccionarios imperfectos. Con el objeto de valorar las posibilidades reales que presentan estas obras para la ayuda en la creación poética, examino la evolución de algunas de ellas. Fuera del alcance de este artículo quedan otras muy relevantes.

\section{Nanus Mirabellius. Polyanthea ( I 503) y sus ampliaciones}

A juzgar por el número de ediciones y la cantidad de veces que se cita la Polyanthea de Nanus Mirabellius, debió de ser una de las obras de erudición más difundidas durante los siglos XVI y XVII. No obstante, su carácter no es exclusivamente poético, sino eminentemente enciclopédico, con un gran peso de la doctrina e historia sagradas. Como otras obras de este tipo, experimentó varias ampliaciones y reorganizaciones ${ }^{9}$. Tras más de cien años y la participación de varios autores y editores, se publica en veinte libros: es apostillada y ampliada primero por Franciscus Tortius y Bartholomeus Amantius (1585) y ampliada y refundida más tarde por Iosephus Langius (1598).

De la primera de sus versiones manejo una edición temprana, parisina de 1512, in folio, en letra gótica, que ha perdido la portada ${ }^{10}$. Tras una «Epistola nuncupatoria» de su autor-fechada en febrero de 1503-, presenta una «Tabula alphabetica» de once páginas

8 Fernando Lázaro CARreter (1979): «Imitación compuesta y diseño retórico en la oda a Juan de Grial», Anuario de estudios filológicos, vol. II, pp. 89-119, Universidad de Extremadura, p. 118.

9 Puede verse la historia editorial del texto, sus reorganizaciones y ampliaciones en Sagrario López PozA (2000): «Polianteas y otros repertorios de utilidad para la edición de textos del Siglo de Oro», La Perinola IV, pp. 191-214, Universidad de Navarra, pp. 197-199.

10 Ejemplar R/20362 de la BNE. El catálogo de la biblioteca ofrece la descripción que falta en la portada a partir de Renouard. Bibliographie de Josse Badius Ascensius, t. III, pp. 85-86: «[Parisiis]: uenundatur ab Ioanne Paruo et Iodoco Badio Ascensio. 1512, Kalend. Octob. [1 de octubre]». El lugar de publicación está determinado por la sede conocida de los impresores. 
que recoge a cuatro columnas sus artículos remitiendo al folio donde se encuentran. El cuerpo de la obra se compone de doscientos cuarenta y siete folios numerados. En el verso del último hay una «Tabula auctorum in toto opere citatorum».

A diferencia de otras polianteas cuyas estructuras acusan el peso de la cosmovisión renacentista y medieval, mantiene una estricta ordenación alfabética, sin agrupar sus entradas en posibles libros temáticos. Además, las entradas que recoge presentan una notable variedad. Así, junto a vocablos seleccionados por su interés humanístico, literario, histórico o sagrado, se encuentran artículos que deben estar en cualquier diccionario general de una lengua: «correctio», «locatio», «oculus», etc. Este carácter de lexicón peculiar se manifiesta desde el principio de la obra con una entrada exclusivamente gramatical: «a, et ab, et abs apud latinos idem significant, quod apud graecos ảંò...». A pesar de que el artículo aduce luego las autoridades de Plinio, Virgilio y Terencio, obviamente la información que ofrece no será de relevancia para un creador literario, especialmente en lengua vulgar. Gran parte de los artículos se componen de un lema -señalado por un calderón, pero también a menudo indiferenciado del resto del texto-, su traducción al griego, una o varias definiciones léxicas -autorizadas o no-, y una o varias citas que autorizan el lema en cuestión en las letras sagradas, clásicas o toscanas. Su procedimiento principal es, por tanto, el de la compilación de loci similes. Algunos de sus artículos presentan una gran profusión de citas y explicaciones, lo que puede producir la impresión de que estamos ante una enciclopedia peculiar. Así, por ejemplo: «amor», «anima», «baptismus», «deus et dea», «ebrietas», «fides», «homo», «peccatum», etc. Muchas de estas entradas complejas anteponen un árbol sinóptico que refleja el desarrollo del artículo.

Todavía en 1604 se edita una versión anterior a la efectuada por Iosephus Langius en 1598: «Lugduni. Sumptibus Horatii Cardon» ${ }^{11}$ recoge las aportaciones de Bartholomaeus Amantius y de Franciscus Tortius, pero no la intervención de Langius. Tal y como reza su portada, se trata de una obra de carácter general orientada a la ayuda de los jóvenes en su estudio, que recoge flores de sentencias tanto griegas como latinas, de autores sacros y profanos, antiguos y modernos. Las aportaciones de los nuevos autores se encuentran en el cuerpo principal del texto y se señalan en los márgenes, al igual que las del primer autor, bien «MIRABELLIUS», bien «AMANTIUS», bien «TORTIUS». La ampliación es notable. El volumen presenta ochocientas cincuenta y una páginas a dos columnas, con un cuerpo de letra inferior al de su predecesora, en un tamaño de página ligeramente superior.

En realidad, esta edición amplía y mejora, pero no integra, pues mantiene diferenciadas las aportaciones de cada autor, a menudo con la repetición de los lemas. Tenemos así, por ejemplo, que «ebrietas» se lematiza tres veces consecutivas: en las páginas 266, 269 y 272 (Mirabellius, Amantius y Tortius). Así ocurre en cada artículo, si bien las aportaciones de los tres autores son del mismo tipo. Puede decirse, por tanto, que Amantius y Tortius estimaron práctico el procedimiento de Mirabellius y decidieron continuarlo, aunque, quizá porque era una obra demasiado conocida -0 quizá por honestidad intelectual-, no dispusieron entre las propias las aportaciones del primer autor, sino que las transcribieron apenas inalteradas. Luego añadieron las suyas en el lugar correspondiente respetando el procedimiento original, sin añadir nuevos lemas, sino exclusivamente ampliando el aparato de definiciones y citas autorizadas.

11 Examino el ejemplar 2/69779 de la BNE. 
Iosephus Langius. Polyanthea noua ( I 598)

La intervención de Iosephus Langius sobre la Polyanthea ya ampliada por Amantius y Tortius será de otro tipo. Con ella la obra alcanzará los veinte libros pero, sobre todo, se sujetará a un orden distinto. Entre las publicaciones de Mirabellius (1503) y de Langius (1598) ha transcurrido casi un siglo, durante el cual la Polyanthea se ha convertido en una obra muy conocida y ha conferido su nombre a un género. Hay de esta obra una gran cantidad de ediciones, casi todas bajo el título de Polyanthea noua, el cual responde realmente a su nueva formulación y planta.

Examino la edición de Frankfurt de 1607 «Sumptibus Lazari Zetneri Bibliopolae», in folio, con cuatro hojas y mil doscientas cincuenta y siete páginas numeradas ${ }^{12}$. Es la segunda edición corregida de otra probablemente del mismo año. En su portada se describe el contenido de la obra, se señalan los autores de la versión anterior y se indican las mejoras que ha introducido Iosephus Langius. Polyanthea noua, de acuerdo con su portada, elimina errores en los títulos y las materias y mejora el orden de los temas que incluye, tanto sacros como profanos. La intervención que se produce es, por tanto, de orden técnico, lexicográfico. Desaparecen las marcas de autoría y las aportaciones de los compiladores quedan ahora mezcladas. Por otra parte, la microestructura se sujeta a la disciplina impuesta por varios epígrafes, no presentes en todos los artículos: «Definitiones et etimologia», «Diuisio», «Loci biblici», «Sententiae biblicae», «Patrum sententiae», «Poeticae sententiae», «Philosophorum sententiae», «Apophthegmata», «Similitudines», «Adagia», «Exempla biblica», «Exempla profana», «Exempla historica», «Hieroglyphica», «Fabulae», «Emblemata», «Scriptores». Esta reelaboración de la microestructura, que se adapta a la estructura del discurso de acuerdo con las retóricas de la época, denota una creciente preocupación por que sus contenidos resulten más accesibles. En cuanto a la selección de sus entradas, es sintomático que la poliantea empiece ahora en «abstinentia» y que hayan desaparecido todos los artículos anteriores: «a, et ab, et abs», «abactor», «abacus», «abdicatio», «abyssus», «abiuratio», «abominatio», «abortiuus», «abrogatio», «absonus», «abstemius».

Es decir, la intervención de Langius en 1598 funde en una las entradas con idéntico lema de los tres autores previos y añade materiales nuevos pero, al mismo tiempo, se desprende de artículos cuyo interés no es específicamente poético o retórico y dota de cierta microestructura uniforme a toda la obra. No avanza la poliantea, por tanto, en un sentido lexicográfico y omniabarcante -si bien mantiene la ordenación alfabética-, sino que se especializa en la ayuda a la creación poética.

\section{Ludouicus CAelius Rhodigini, LeCtionum ANTIQUARUm ( I 5 I6)}

Fue muy utilizada por los poetas y predicadores áureos, quienes extraían de esta peculiar enciclopedia multitud de anécdotas, ejemplos y datos con los que ilustrar sus poemas y sermones al tiempo que se revestían de erudición.

12 Ejemplar 7/14858 de la BNE. Con portada, dedicatoria, prólogo del autor y un poema en dísticos latinos de A. Hellius. López Poza (2000), op. cit., pp. 198 y 199, examina una edición de 1621 -«Francofurti, Sumptibus haeredum Lazari Zetzneri»-, en cuya portada figura el título: Floregii magni, seu polyantheae floribius nouissimis sparsae, libri XX. 
De acuerdo con la portada de su primera edición, aldina de 1516 - «Sicuti antiquarum lectiomun commentarios concinnarat olim Vindex Ceselius, ita nunc eosdem per incuriam interceptos reparauit Lodouicus Caelius Rhodiginus...»- su autor intenta recomponer los libros perdidos de los Comentarios de las lecciones de los antiguos de Vindex Ceselius, recogiendo tanto flores teológicas como de Platón, de Aristóteles y de «otros herejes». La obra experimentará un notable aumento debido al mismo Ludouicus Caelius: de los dieciséis libros de la primera edición hasta los treinta de las más completas. Comparo la citada edición veneciana con otra muy tardía y aumentada, genovesa de 1620.

En la edición de 1516, «Venetiis in aedibus Aldi, et Andreae soceri», el volumen in folio se encuentra divido en dieciséis libros con unos treinta capítulos cada uno y un total de ochocientas sesenta y dos páginas ${ }^{13}$. Tras la dedicatoria y el prefacio del autor, la obra presenta tres índices ${ }^{14}$. El primero reproduce el orden de los libros y capítulos: «Elenchus, siue index breuis eorum, quae capitibus singulis, toto continentur uolumine». El segundo, en el mismo orden en que aparecen en la obra, contiene algunas de las autoridades citadas: «Index eorum, quae scitius, enarratiusque explicantur, in diuersis obseruata auctoribus». El tercero, sin duda el más original, ofrece en veinticuatro páginas a cinco columnas todas aquellas cosas contenidas en el libro dignas de atención: «Elenchus, siue syllabus rerum dignarum cura, quae hisce lectionum antiquarum commentariis continentur, ut uel citra incommodum, quod quis concupierit, quaerat modo, et consequator A'KONHTÍ [griego con caracteres latinos en el original]». Es decir, lematiza todos aquellos vocablos, motivos, temas, autores y cualquier otro elemento digno de tenerse en consideración sin limitarse a los epígrafes o títulos o lemas o cualquier otra indicación estructural de la obra, sino extrayendo sus materiales del cuerpo del texto, ordenándolos de manera alfabética y señalando luego las páginas donde se encuentran. Será precisamente este índice uno de los mayores logros de este singular compendio de la sabiduría de los antiguos, pues permite su empleo como obra de consulta. En sucesivas ediciones se mantendrá, perfeccionará, aumentará en mayor medida que la propia obra y se anunciará en la portada como uno de sus atractivos: «... cum rerum et uerborum indice copiosissimo» ${ }^{15}$.

La edición de Génova de 1620, «Excudebat Philippus Albertus», es un volumen in folio, sin paginación -se numeran, en cambio, las mil setecientas veinte columnas del cuerpo del texto, dos en cada página-, compuesto por portada, tres prefacios, treinta libros, dos índices de autores y el mencionado y extenso «Index uocum et rerum» ${ }^{16}$. Afirma en su portada que los treinta libros de la edición, reconocida por el autor, han sido aumentados en más de la tercera parte gracias a una meritoria explicación, tanto de voces como de cosas diversas, impenetrables y recónditas, para que se vea, si bien con dificultad, reunida en una sola la historia del hombre. Se trata de una obra a la que puede denominarse tanto tesauro como cornucopia de la lengua. Añade que se trata de la última

13 Utilizo el ejemplar R/18942 de la BNE. En el colofón: «Venetiis in aedibus Aldi, et Andreae soceri. Mense februario MDXVI».

14 Hay aún un cuarto índice, tras el cuerpo de la obra, que consiste en una fe de erratas: «Index eorum, quae per incuriam sunt insigniter ab impressoribus admissa, peccatum et in aliis, opinor, sed ita, ut operam sibi uel mediocriter possit eruditus in eo praestare».

15 En la portada de la edición que se describe enseguida.

16 Ejemplar 2/57521 de la BNE. 
edición, a la que acompaña un muy abundante índice «rerum et uerborum». La declaración de intenciones de su portada es, pues, la habitual en este tipo de obras. Se trata de una summa. Su autor pretende reunir en una sola obra todo cuanto afecta al hombre.

Dada la vastedad de estos propósitos, los capítulos -en torno a treinta en cada libro- se suceden sin orden aparente, con una pobre cohesión. Los libros no presentan título y vienen precedidos por un prefacio-dedicatoria que no alude a sus contenidos. Tampoco hay un índice de materias que permita hacerse una idea de la articulación de la obra. El orden expositivo presenta, pues, la compleja variedad del mundo de manera fragmentaria, como las polianteas, y, al mismo tiempo, de forma discursiva y expositiva, como los tratados científicos. Los primeros libros, que tratan cuestiones previas como Dios, el hombre y el mundo, mantienen un orden jerarquizado que desaparece progresivamente para configurar en los últimos una verdadera miscelánea. El primer capítulo del primer libro considera si corresponde a Dios algún nombre: «An Deo congruat nomen aliquod, obseruata ex Theologumenon libris». El segundo y el tercero tratan de temas teológicos, pero también bíblicos, así como sobre la naturaleza del hombre. Los tres primeros capítulos versan, pues, sobre aspectos relacionados con Dios, con el mundo y con el hombre, en la gradación propia de un libro de teología, pero también de un tratado científico de raíz aristotélica. Ya el capítulo cuarto introduce cuestiones filosóficas y mitológicas como el coro de las musas, Apolo, la consideración pitagórica de la tierra como una estrella, las diosas mencionadas por Platón, etc. Enseguida deriva, pues, de los planteamientos teológicos iniciales a la descripción de elementos paganos y pseudofilosóficos. Tampoco la composición de los capítulos responde a un criterio claro, sino que la mayoría de ellos presenta en desorden un cúmulo de conocimientos teológicos, ideas filosóficas, mitos, citas literarias, anécdotas históricas, nociones precientíficas, etc.

Así pues, Lectionum antiquarum se inicia con el orden expositivo propio de un tratado que pretende ser una summa de todos los conocimientos de la época, pero enseguida se extravía y opta por la acumulación más o menos trabada de los conocimientos que a sus autores les parecieron necesarios para ser un hombre docto. Existe cierto orden en el principio, pues trata de cuestiones generales que soportan bien una jerarquización de acuerdo con principios teológicos, pero este orden se disuelve una vez avanzada la obra, al alcanzar los detalles menos susceptibles de admitir cualquier orden. Propio del estilo discursivo de Lectionum antiquarum, pues sus autores, o alguno de ellos, no tienen siempre presente que se trata de una obra cuya finalidad es ser consultada, es también la presencia de expresiones que refieren a lo ya dicho para evitar la repetición, pero sin especificar dónde se ha de encontrara dicha información. Por ejemplo: «Verum quia multa diu iam de mundo uerba facimus...» («Liber primus», cap. V), «A Dea uero quae hactenus de capitis modulata ratione diximus...» («Liber uicesimus», cap. XIII), etc. Bien es cierto que estas referencias aluden a pasajes inmediatamente anteriores, pero en capítulos distintos.

Al finalizar el último de los treinta libros aparecen dos índices de autores y, tras ellos, cierra el volumen un extenso índice de ciento veintiséis páginas a tres columnas: «Index uocum et rerum singularum cognitu necessariarum foecundissimus». El método es el mismo que el descrito para la edición aldina realizada en vida de Caelius pero, en este caso, la disposición tipográfica del cuerpo de la obra -en dos columnas- cumple un papel importante en el acceso a sus contenidos. En el espacio intermedio de las dos columnas figura una serie alfabética en mayúscula -de la «A» a la «G»-que, combinada 
con el número de columna que figura en la parte superior de cada una de ellas -de «1» a «1720»-, servirá para localizar los contenidos en la parte principal de la obra. El procedimiento para la elaboración de este índice, al igual que su precedente en la edición aldina, hubo de ser el de volcado o despojo. Es decir, una vez elaborado el cuerpo de la obra, se procedió a señalar en él los posibles lemas que deberían formar parte del índice. Además, su configuración facilita la consulta lematizando lugares dos y tres veces con distintos núcleos semánticos. Por ejemplo: el lugar «13G», en que se expone la afirmación de Pitágoras de que la Tierra es una estrella (en el título del capítulo: «Terram esse stellam unam, ex Pythagora»), aparece en el índice en los siguientes lugares: en la «P», «Phithagorae de terra opinio», en la «T», «terram Pythagorae, unam esse e stellis». En cambio, no aparece en «stellae» ni en «sidera», que se remiten mutuamente.

\section{RAVISIO TEXTOR. EPITHETORUM OPUS (I 5I 8)}

Las tres obras de erudición de Jean Tixier de Ravisi (1480-1524), profesor de retórica en el colegio de Navarra y rector en la Universidad de París ${ }^{17}$-Epithetorum opus (1518), Cornucopiae (1519) y Officinae (1520) - se editan a lo largo de al menos siglo y medio y constituyen con seguridad obras de referencia de la erudición europea durante más de dos siglos. Los libros de Ravisio Textor no son ya compendios generales o parciales del saber, sino verdaderos manuales de ayuda para la composición de la obra literaria, especialmente de la poética.

Sin duda, Epithetorum opus, una serie alfabética de sustantivos con sus epítetos elaborada por un profesor de gramática y retórica, debió tener, en primer lugar, una orientación académica, lo cual no excluye que autores, consagrados o no, pudieran también utilizarla para ayudarse en la escritura y para dotarse de erudición.

Bajo cada lema de Epithetorum opus se presenta la definición del sustantivo y, a continuación, a tres columnas, los epítetos que le convienen, un verso que autoriza la adjetivación y la fuente -autor y obra- de donde se ha tomado el verso, si bien esta última indicación resulta a menudo incompleta.

El volumen que examino, de 1612, «Basileae, Apud Conradum Waldkirchium» ${ }^{18}$, forma una unidad con significado cuyo propósito declarado es la enseñanza de la versificación latina. Se trata de un volumen in octavo, con portada, ochocientas ochenta y nueve páginas que configuran el libro principal, seguido de la clave de las abreviaturas de los autores citados y otros tres libros, sin paginar, con consejos para la práctica poética.

El primero de los libros complementarios es un pequeño tratado escolar de prosodia de veintinueve páginas. El segundo, de catorce, cuyo autor es Georgius Sabinus, es un tratado de poética acerca de la manera de imitar a los poetas antiguos. En las ocho páginas del último de los libros, Georgius Fabricius expone sus recomendaciones para la utilización correcta de los epítetos contenidos en el libro principal.

17 Tomo la noticia biográfica de Pedro Ruiz Pérez (1990): «Los repertorios latinos en la edición de textos áureos. La Officina poética de Ravisio Textor», La edición de textos. Actas del I Congreso Internacional de Hispanistas del Siglo de Oro, Pablo Jauralde Pou (coord.), Dolores Noguera Guirao (coord.) y Alfonso Reyes (coord.), pp. 431-440, Madrid, Tamesis Book Limited, p. 432.

18 Epithetorum opus perfectissimum, ejemplar 2/5352 de la BNE. 
Es notable que en Epithetorum opus apenas se consignen usos metafóricos de los sustantivos que recoge. Por poner un ejemplo, los ocho epítetos de la entrada «abies» suponen la interpretación literal del lema, equivalente a 'árbol abeto'. Ninguno de ellos presenta el sentido traslaticio, tan habitual, de 'barco', en sinécdoque, la materia por el objeto, bien acreditado desde Virgilio (Aeneis VIII, v. 91): «Labitur uncta uadis abies...»" ${ }^{19}$, hasta Góngora (Soledad primera, vv. 413 y 414, aludiendo a las carabelas de Colón): «Abetos suyos tres aquel tridente / violaron a Neptuno». Por el contrario, aparecen ocho adjetivos autorizados por los siguientes versos: «Enodisque abies, curuataque glandibus ilex» (Ovidio, libro 10); «Hinc audax abies et odora in uulnere pinnus» (Estacio); «Apta fretis abies, bellis accommoda cornus» (Claudiano); «Lenta salix, redolens abies, descendit in aequor» (Quintiliano); «Caeditur atque abies pronis umbrosa lacertis» (idem); «Tosti [alti] stant parietes deformati, atque abiete crispa» (Cicerón 1.3. Quastio. Tusc.); «Hic procera abies, crebris quam lata securis ictibus excudit» (Mantuano [Virgilio]); «Pro ripis crinita abies, et acuta cupressus» (idem). El ejemplo de «abies» es sintomático, pues tampoco se encuentran sentidos traslaticios en otras entradas.

$\mathrm{Si}$ «abies» presenta ocho adjetivos, «fatum», en cambio, refleja noventa y tres, con sus autoridades y referencias. No siempre presenta Epithetorum opus, no obstante, tanta profusión en las definiciones, abundancia en los epítetos o precisión en las fuentes. Así, por ejemplo, las entradas consecutivas «Euterpe» $\mathrm{y}$ «Euxinus» se limitan a una definición, un verso y la cita del autor de donde se toma, Quintiliano y Virgilio respectivamente: «Euterpe, una e nouem Musis. / Sancta. Dulciloquos inflat calamos prudentia sanctae Euterpes. Quint.»; «Euxinus, prius Axonus. / Gelidus. Tunc gelidi sinus Euxini, tunc alta propontis. Mant.»

Como casi toda obra de erudición, Epithetorum opus se muestra, pues, desequilibrada en sus contenidos, extremadamente copiosa en algunas de sus entradas pero parca en otras muchas. Hay, además, términos que Epithetorum opus no recoge, aun siendo muy frecuentes en la poesía clásica y toscana. Así, por ejemplo, no figura «nympha», que podría aparecer con los epítetos «pulchra», «leniter», etc.

Debe, por tanto, considerarse con precaución la verdadera influencia de Epithetorum opus en la producción poética europea a partir de 1518, pues si bien se trata probablemente de la obra más perfecta en su género, son muchas sus carencias y muchos los contenidos que no son verdaderamente productivos para la poética por tratarse de lugares comunes ampliamente conocidos.

\section{Ravisio TeXtor. OFFICINAE (I520)}

Los dos tomos de las Officinae de Ravisio Textor contienen una serie de temas históricos, mitológicos y literarios agrupados en epígrafes y entradas. Su título perderá el plural al ser fundidos en uno -de Officinae a Officina-, intervención que llevará a cabo Conrado Lycosthenes en la edición de Basilea de 1552. Debe mucho a Epithetorum opus, de donde copia gran parte de sus definiciones, si bien no incluye su lista de epítetos ni ordena sus contenidos alfabéticamente, sino que primero los agrupa por temas y luego, en ocasiones, dota a la estructura de los epígrafes con un orden alfabético a menudo impreciso.

\footnotetext{
19 «Los embreados abetos se deslizan por el río...».
} 
Sus contenidos son variopintos. Los primeros epígrafes del primer tomo agrupan diversas maneras de morir ${ }^{20}$ : «Terra absorpti» (I, 70), «Gaudio et risu mortui» (I, 75), «In uenereo actu mortui» (I, 76), «In latrinis mortui aut occisi» (I, 82). Hay también utilísimas listas sobre toda clase de hombres: «Homines male olentes» (I, 112), «Stulti, et insipientes» (I, 123), «Indocti, et qui literas oderunt» (I, 169), «Animalium et aliarum rerum amatores» (I, 224), «Piscatores, et urinatores» (I, 330), etc. El segundo tomo comienza con la nómina de algunas serpientes, «Serpentum quorundam nomina» (II, 3), y reúne todo género de listas: «Viri celebres mortui in aliena terra» (II, 51), «Prodigia et portenta diuersa» (II, 71), «Auium et aliorum animalium inimicitiae» (II, 180). El segundo tomo, pues, contiene materiales análogos a los del primero, por lo que ha de interpretarse que se trata de una ampliación que no pudo imbricarse en el mismo tomo hasta que no se reelaboró la organización de la obra.

No obstante, no todos los contenidos de las Officinae son excéntricos. Se pueden también encontrar, entre otros de utilidad, los siguientes epígrafes: «Furiae tres» (I, 122), «Mulieres doctae $»^{21}$ (I, 233), «Nautae nonnulli» (I, 329), «Parcae, deae fatales» (II, 126), «Nymphae diuersae» (II, 130), «Pictores diuersi» (II, 216), «Historiographi plerique Graeci et Latini» (II, 380), etc. Hay otros, pocos, cuyo contenido es eminentemente retórico: «Descriptio ortus diei» (I, 403), «Descriptio meridiei» (I, 406), «Descriptio noctis, seu aduentus eius» (I, 407).

La primera edición data de 1520. La de Conrado Lycosthenes -Basilea, 1552- reordena y enmienda el original. A partir de esta fecha, algunas ediciones se basan en la organización original de Textor y otras en la de Lycosthenes. Manejo dos ediciones más tardías: «Sumptibus Petri Rigaud, Lugduni, 1602, editio tertia», que responde aún a la ordenación original de Ravisio Textor, y «Apud Milochum, Venetiis, 1658», que recoge las modificaciones de Lycosthenes ${ }^{22}$. Ambas incluyen al final Cornucopiae, del mismo autor, consistente en una lista con definiciones y autoridades de lugares donde abundan diversas cosas - «Loca diuersis rebus abundantia»-, opúsculo que, si bien se edita también de manera individual, suele aparecer como complemento de las Officinae.

Lugduni 1602 está divida en dos tomos, con un índice alfabético al final de cada uno, «Locorum insignium index tomi primi» $\mathrm{y}$ «Locorum insignium index tomi secundi». Los índices remiten a los epígrafes temáticos de que constan ambos tomos. Cada uno de los dos índices ocupa solo cuatro páginas, pero es la única orientación que permite utilizar la obra como libro de consulta. Por otra parte, el orden de sus entradas es caprichoso y los índices son poco útiles. La dificultad estriba en la poco lograda lematización temática que presenta la obra. La arbitrariedad parece la tónica en las ediciones Lugduni de Officina. Su autor ha procedido volcando datos que le parecieron susceptibles de agruparse bajo lemas significativos. Sin embargo, tanto la división de los significados como la elección de los lemas son cuestionables y, por ello, difícilmente el consultante predecirá dónde encontrar lo que busca. No obstante lo impreciso de los índices y lo arbitrario de la lematización, cabe la posibilidad de leer completamente ambos índices, lo cual proporciona una idea general de

20 Tomo los epígrafes de la edición «Sumptibus Petri Rigaud, Lugduni, 1602, editio tertia», ejemplar 3/68134 de la BNE, que refleja el texto preparado por Textor sin la alteración posterior de Lycosthenes.

${ }_{21}$ Está ampliamente analizado el uso de la nómina de mujeres doctas de las Officinae por parte de Lope de Vega en la comedia La doncella Teodor. Puede verse en GonZÁleZ-BARRera (2007), op. cit.

22 Respectivamente, los ejemplares 3/68134 y 2/980 de la BNE. Puede consultarse en línea la edición de 1560, «Lugduni. Apud Haered. Seb. Griphii» escaneada y transcrita por la universidad de Mannhein:

http://www.uni-mannheim.de/mateo/camenaref/ravisius/ravis1/Ravisius_officina_1.html (6/1/12). 
la obra. Además, su autor trata de facilitar la búsqueda reflejando en ocasiones en el índice la misma entrada bajo formas distintas. Por ejemplo: «Effoeminati, et molles» $\mathrm{y}$ «Molles, effoeminati, et elegantes», en el índice del primer tomo, refieren ambos a «Molles, effoeminati, et elegantes» (I, 195, a pesar de la errata de la primera de las indexaciones, que remite a la página 175). En el índice del tomo segundo: «Augures et aruspices» $\mathrm{y}$ «Vates et augures» remiten ambos a «Vates, augures, et aruspices» (II, 61). Los índices no tienen en cuenta las preposiciones que sí aparecen en los epígrafes y varían el orden de las palabras cuando el epígrafe no comienza con el núcleo semántico. Por ejemplo: «Descriptio noctis, seu aduentus eius» (I, 407) $\rightarrow$ «Noctis descriptio» (en el índice), etc. Sin embargo, no ocurre así en todos los casos. Por ejemplo, aquellos epígrafes que comienzan con la palabra denominationes mantienen sus títulos y aparecen en la «D». Así, por este orden: «Denominationes a naturalibus, seu accidentariis casibus» (I, 145), «Denominationes a uariis artium professionibus» (I, 135), «Denominationes a genere» (I, 148).

Algunos lemas son cajones de sastre, especialmente aquellos que parecen finalizar determinadas series y, por tanto, cumplen la exigencia de recoger todo lo que ha quedado fuera. Es el caso de «Alii parricidae» (I, 47), después de los epígrafes que contienen diversos tipos de parricidio, «Morbi diuersi» (I, 97-109), al final de la larga serie que recoge maneras de morir, etc. En otros casos, los artículos constituyen pequeños glosarios de un campo histórico, literario o científico particular. Así, por ejemplo «Morbi diuersi» (I, 97-109), «Denominationes a uariis artium professionibus ordine literarum» (I, 135-145), «Telorum bellicorum, et gladiorum nomina» (I, 294-297), «Pisces diuersi» (I, 332-351), «Populorum diuersi mores et ritu uarii, ordine literarum» (I, 351-386), etc.

La separación de los significados resulta bastante deficiente. Puede aducirse el siguiente ejemplo: «Mulieres bellicosae et masculae uirtutis» (I, 241-244) a la que sigue «Amazones» (I, 244 y 245). Obviamente, el primer epígrafe debería comprender al segundo en lugar de estar al mismo nivel. De hecho, en ambos figura la entrada «Penthesilea», reina de las amazonas, si bien varía su definición.

Al igual que en Lectionum antiquarum no está del todo asentada la idea de que se trata de un libro de consulta que no corresponde a un orden discursivo sino al fragmentario propio de los diccionarios y enciclopedias. Así, por ejemplo, escribe el autor: «Iam diximus Daphnem Penei fluminis filiam adamatam Apollini...» (I, 191), «Argonautae (ut iam diximus) dicintur heroes illi...» (I, 329). No obstante, este tipo de comentario es también frecuente en otras obras con carácter lexicográfico más marcado, como el Tesoro de la lengua castellana o española de Sebastián de Covarrubias. Algunos de los epígrafes presentan autoridades. Así, «Currus deorum quibus animalibus trahantur» (I, 323), tras presentar los tiros de los carros de dieciséis dioses y diosas, aduce las autoridades de Poliziano y de Pico della Mirandola. Otros epígrafes están formados exclusivamente por citas literarias. Así: «Gentium propriae epitheta» (I, 150), «Argumenta ab impossibili, ex diuersis poetis» (I, 387), etc.

\section{ConRado Lycosthenes. OfFICINA IoANNIS RAUISII TeXTORIS NIUERNENSIS (I552)}

Al igual que la Polyanthea de Mirabellius, las Officinae sufren una intervención técnica que trata de mejorar su presentación, pero no necesariamente orienta mejor en el acceso a sus contenidos. Con la reorganización de Lycosthenes, la obra adopta un orden 
expositivo próximo a la concepción renacentista del cosmos. Sus contenidos previos se dividen y se agrupan en siete libros temáticos -«Titulus»- al tiempo que se suprimen los índices alfabéticos. Esta supresión indica quizá que el nuevo autor considera suficiente la ordenación de los contenidos de la obra mediante su división en libros, pero, sobre todo, revela que Conrado Lycosthenes no pretende una obra de consulta, sino un tratado.

Los siete títulos o libros son: «De Diis eorumque cultu», «De mundo», «De tempore et eius partibus», «De homine», «De magistratu», «De artibus et artificibus», «De uariis uirtutibus ac uitiis». Trata, por lo tanto, de establecer un criterio taxonómico sobre una obra cuya estructura era caótica. Los elementos que conforman las fantásticas enumeraciones de Officinae son ahora fragmentados, separados, refundidos y conducidos a otro lugar, pero no se producen apenas adiciones en los contenidos.

Venetiis 1658 -con la intervención de Conrado Lycosthenes de 1552- presenta, pues, notables modificaciones en la estructura de la obra y orden de las entradas: subsana algunos errores e introduce otros, funde en uno los dos libros de las primeras ediciones, añade algunos materiales y expurga otros, rompe, divide y agrupa nuevamente los contenidos en siete títulos, organiza de manera distinta los epígrafes, sustituye los índices alfabéticos por otro conforme al orden expositivo de la obra, con sus títulos y epígrafes -«Capitum siue titulorum Officinae Ravisii Textoris index»-, y contiene, al final, ciento cuarenta y nueve cartas breves de Ravisio Textor. En su portada, si bien no menciona a Lycosthenes, declara haber sido «diligenter emendata, aucta, et in longem commodiorem ordinem reducta».

\section{CONSIDERACIONES FINALES}

Los compendios del saber medievales y de la Antigüedad difieren de las obras de erudición renacentistas en algo esencial: no se conciben como obras de consulta, sino como textos expositivos que responden a un orden discursivo, dialogal o a ningún orden, cuyos autores exigen su lectura completa. En cambio, la Polyanthea de Mirabellius, que abre el género, organiza ya sus materiales de modo que la disposición del conocimiento permite la lectura fragmentaria del texto en función de la eventual necesidad del lector. Se dan otras divergencias fundamentales: aquellos son utilizados como fuente por las polianteas, estas dividen sus contenidos, los dispersan y vuelven a reunirlos bajo una ordenación alfabética que se manifiesta en el cuerpo del texto o en índices de diversa composición. Tanto la ordenación alfabética como los índices convierten cuanto tocan en obras de consulta orientadas a la ayuda en la imitación o como fuente para la inventiva. Tal y como se ha visto, sucede así específicamente con el «Index uocum et rerum» de Lectionum antiquorum, pero ocurre lo mismo con los índices de otras obras de erudición. Es también el caso de la obra de Natale Conti -Mythologiae, siue explicationum fabularum, libri decem (1551)-, que carece de lematización y ordenación alfabética, pues su orden se aproxima más al discursivo de Metamorphoseon o Genealogia deorum gentilium que al de un diccionario, y, sin embargo, fue ampliamente utilizada como fuente de conocimientos mitológicos ${ }^{23}$.

23 Véase Rosa María Iglesias Montiel y María Consuelo Álvarez Morán (1988): edición de Natale Conti, Mitología, Murcia, Universidad, p. 33. Además, la edición de Frankfurt de 1584 «Apud Haeredes Andreae Wecheli» contiene tres índices tras otra obra del mismo autor -«De Venatione»- contenida en el mismo 
La dicotomía uoces et res, por otra parte, planteada en los índices no es exactamente traslado del par aristotélico res et uerba -reflejo también de la naturaleza dicotómica del signo lingüístico-, sino de una dificultad esencial de algunas obras lexicográficas: la lematización de elementos heterogéneos: léxicos y temáticos. No se trata, por tanto, de índices de doble sentido, léxico e ideológico, sino de índices que incluyen tanto entradas léxicas puras como complejas, tanto en su aspecto formal (polimorfismos, homonimias, etc.) como en su aspecto conceptual (temas, motivos, etc.).

Por otra parte, las ampliaciones y reorganizaciones efectuadas sobre obras preexistentes apuntan a un hecho fundamental en la lexicografía: los diccionarios y las obras enciclopédicas son obras de muy lenta elaboración que, independientemente de la cantidad de sus entradas y contenidos, se pueden mejorar con un nuevo orden que los dote de mayor utilidad. Es decir, la conciencia por parte de los autores de que el acceso a los contenidos es parte de la eficacia de la obra crece con la asunción de nuevos principios organizativos. Parece que primero se vuelcan los contenidos con una ligera idea del orden que se va a imponer y solo luego, a la vista de los materiales recogidos o de la experiencia como lector, se modifica su organización.

En cuanto a la obra cuya influencia sobre los poetas del Siglo de Oro ha merecido mayor atención crítica, merece la pena señalar que en ambas versiones de las Officinae se pueden hallar motivos, sucesos, anécdotas, personajes y pensamientos interesantes, pero es difícil encontrar precisamente lo que se busca, pues sus contenidos son diversos, ambiciosos y reflejan las inquietudes y preferencias de su autor. Por el contrario, es fácil toparse con materiales imprevistos que avivan la inventiva pero también desvían la atención de la búsqueda primera. Sin duda, cualquiera de sus ediciones ofrece una relativa ayuda a la creación poética -pues se describen usos poéticos, eruditos, historiográficos, filosóficos-, pero su compleja organización es una desventaja si se considera como una obra de consulta y, si bien la intervención de Lycosthenes tratará de mejorar este aspecto, será preciso familiarizarse con la estructura de la obra para orientarse en su manejo. Además, la mayoría de sus contenidos no parecen realmente apropiados para ayudarse en la creación poética. Es decir, las enumeraciones, los ejemplos e, incluso, los lugares retóricos que se encuentran en las Officinae sirven, quizá, para completar una enumeración altisonante, para extraer ejemplos moralizantes o para satirizar determinadas costumbres, pero, a ojos de un poeta inspirado, no pasarán de ser un ejercicio escolar próximo a los que proponen libros de ejercicios retóricos como las Progymnasmata de Aftonio. Explicar las causas por las que las Officinae sirvieron a Lope en no pocas ocasiones queda lejos de las posibilidades de este artículo.

volumen. El primero y más extenso ordena todo tipo de cosas memorables contenidas en los libros de Mythologiae: «Index rerum memorabilium quae in mithologicis libris continentur». El segundo recoge regiones, ciudades y lugares cuyos nombres tienen su origen en los dioses antiguos: «Regionum, urbium, locorumque nomina, quae originem ceperunt a filiis uariorum Deorum antiquorum». El tercero reúne alfabéticamente aquellas plantas y animales que fueron consagradas a los dioses antiguos: «Quae plantae, et quae animalia quibus Diis fuerint antiquitus consecrata». 